\title{
Evaluation of The Effectiveness of Sigmoid Resection for Children with Intractable Idiopathic Constipation with Megarectosigmoid
}

\author{
Mohamed Magid ${ }^{1, *}$ MSc., Amin Abo Kifa ${ }^{1}$ MD., Mohamed Mahfoz ${ }^{1}$ MD.
}

* Corresponding Author:

Mohamed Magid Mohamed

Drmohamedmagid@hotmail.com

Received for publication January 27, 2021; Accepted March 19, 2021; Published online March 19, 2021.

Copyright 2020 The Authors published by Al-Azhar University, Faculty of Medicine, Cairo, Egypt. All rights reserved. This an openaccess article distributed under the legal terms, where it is permissible to download and share the work provided it is properly cited. The work cannot be changed in any way or used commercially.

doi: 10.21608/aimj.2021.47437.1406

${ }^{1}$ Pediatric Surgery Department, Faculty of Medicine, Al-Azhar University Cairo, Egypt.

Disclosure: The authors have no financial interest to declare in relation to the content of this article. The Article Processing Charge was paid for by the authors.

Authorship: All authors have a substantial contribution to the article.

\section{INTRODUCTION}

Constipation is one of the most common childhood problems occurring in about 3\% of children. Patients who have intractable idiopathic constipation with or without encopresis that is unresponsive to Bowel Management Program(BMP) with no underlying organic cause are the main concern of this study. ${ }^{1}$

Those children usually suffer from fecal soiling, abdominal pain, abdominal distension, with a serious psychological problems of severe social rejection that often results in a poor quality of life and delayed social development. ${ }^{2}$ Reports on surgical treatment of (FC) with Megarectosigmoid by Sigmoidectomy or Rectosigmoidectomy to reduce the redundant dilated poorly functioning colonic length, has shown a subsequent reduction of the transit time leading to the reduction or even abolishing the use of laxatives and consequently markedly improves the state of impaction and pseudo-encopresis. ${ }^{3}$

The aim of this work was to evaluate the effectiveness of Sigmoidectomy with or without partial removal of the rectum in solving the problem of intractable FC in children with Megarectosigmoid.

\section{PATIENTS AND METHODS}

This is a case series study conducted on 20 patients suffered from intractable FC, after failure of all medical managements for at least 6 months. Those 20 patients were selected from more than 250 patients of functional constipation. All patients were operated at Pediatric Surgery Department, Al-Azhar University Hospitals. This study was conducted over 30 months from February 2018 to July 2020.

Inclusion Criteria: All patients were complaining of intractable (resistant to be treated by the BMP for up to 6 months) idiopathic constipation (no obvious 
cause could be detected although the performance of a very sophisticated investigations) with Megarectosigmoid with or without Pseudoencopresis, and their ages were more than 4 years. Exclusion Criteria: Patients were excluded if they had constipation without Megarectosigmoid or with any evidence of organic cause of constipation or responded to the Bowel Management Program.

All Patients were subjected to History taking and full clinical examination including a through rectal examination for search of any sign of organic cause.

Investigations: All patients were subjected to Plain $\mathrm{x}$ - ray erect, Contrast enema without preparation for exclusion of Hirschsprung disease and measuring the Recto-Pelvic Ratio (RPR) in all cases by dividing the diameter of the rectal width by the diameter of the linea transversa of the pelvis. This method provides objective and reproducible values for the size of the rectum. An RPR above 0.61 suggests a megarectum with a mean of 0.68 in all functional constipation patients ${ }^{4}$. Defecography in cooperative 14 patients was done to search for any associated acquired problems as rectoceles, or perineal descent syndrome. EMG was done to all cases, if showed marked muscle weakness. MRI pelvic floor muscles and spine was done to rule out true incontinence. Rectal biopsy was done to all cases before Sigmoidectomy. Anal Manometery was done to the suspicious cases to evaluate the Recto anal Reflexes, Preoperative work up such as Complete blood count and coagulation profile was done before surgery.

Scoring Method: we used the Pediatric Incontinence Constipation Score (PICS) ${ }^{5}$ and the Rome III Criteria ${ }^{6}$ to evaluate the clinical condition of our patients pre and post-operatively.

The scoring system is based on a questioner answered by the childcare giver for every answer the patient is awarded a score that later on can give us an idea about the state of Incontinence and constipation regarding the PICS, while in Rome III Criteria the description of constipation was evaluated accordingly.

Methods: We used a step wise way in dealing with our patient (Figure-1), which is better showed in Figure (1). Bowel Management Program was offered to all patients despite their previous managements. We also followed the National Institute for Health and Clinical Excellence (NICE) guidelines ${ }^{7}$. This Program consisted of 3 lines of managements (Dietary, Medication and Psychological).

Medication management consists of 3 steps (Disimpaction through repeated enemas, Laxative trials and Maintenance). All patients followed a strict high fiber diet (Dietary) with psychological management (Toileting behavior, Psychological support, Reward Scheme). Patients that failed all our trials for medical management (for at least 6 months), that were submitted to the surgical treatment by using the concept of Sigmoidectomy with or without Partial Proctectomy (Rectosigmoidectomy). The aim of all the techniques was to resect most of the redundant (dilated, elongated, poorly functioning sigmoid colon) with partial removal of the rectum. Three surgical techniques were used, Open Rectosigmoidectomy, Transanal Pull-through Soave, and Laparoscopic Assisted Transanal Colectomy (or Needlescopic)

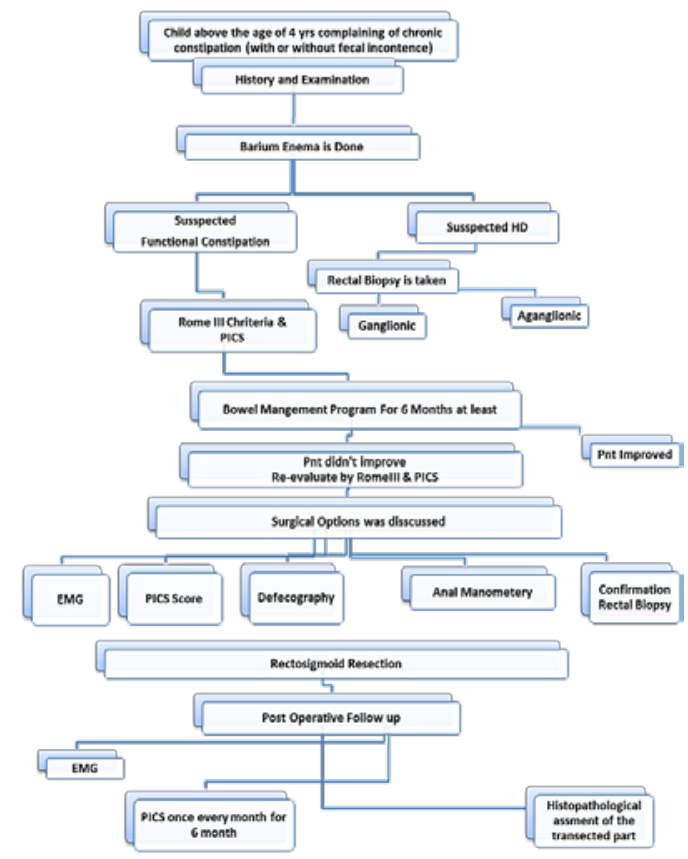

Fig. 1: STEP WISE APPROACH

\section{Statistical Analysis:}

Data were fed to the computer and analyzed using IBM SPSS software package version 20.0. (Armonk, NY: IBM Corp) Qualitative data were described using number and percent. The KolmogorovSmirnov test was used to verify the normality of distribution Quantitative data were described using range (minimum and maximum), mean, standard deviation, median and interquartile range (IQR). Friedman test for abnormally distributed quantitative variables, to compare between more than two periods or stages and Post Hoc Test (Dunn's) for pairwise comparisons. Cochran's test for abnormally distributed quantitative variables, to compare two periods or stages and Post Hoc Test (Dunn's for pairwise comparisons. ANOVA with repeated measures for normally distributed quantitative variables, to compare between more than two periods or stages, and Post Hoc test (Bonferroni adjusted) for pairwise comparisons. McNemar Test Used to analyze the significance between the different stages. The confidence interval was set to $95 \%$ and the margin of error accepted was set to $5 \%$. So, the pvalue was considered significant as the following: Pvalue less than 0.05: Non-significant (NS). P-value More than 0.05: Significant (S). P-value less than 0.01; Highly significant (HS).

\section{RESULTS}

There was a male predominance of approximately $2: 1$. The ages ranged from $4-13$ years old (mean=8.48). Constipation was the main complain (100\%), followed by soiling in 11 cases (55\%), abdominal pain in 12 cases (60\%), abdominal 
distention in 16 cases (80\%). The duration of symptoms ranged from 2 to 11 years (mean=4.64 \pm 2.57 ). Ten cases $(50 \%)$ complained of associated urinary incontence especially nocturnal. Per Rectal (PR) examination showed soiling in 11 cases (55\%), no gripping was elected in all cases and hard stool was evident in 12 cases (60\%), with good state of sphincter in all cases. Barium enema showed hugely dilated elongated rectosigmoid, The S shaped sigmoid length was nearly doubled, the RPR ranged from 0.59-0.83 (mean $=0.7 \pm 0.06$ ). Defecography was done in 14 cases (70\%), Six cases (30\%) were uncooperative during the investigation.

Nine cases (64.3\%) of them had an abnormal figure in defecography. Eleven cases had degree of perineal descent $(78.5 \%)$ ranging from 1 (mild) to 6.5 $\mathrm{cm}$ (sever)(mean=3.4). Also 6 cases $(42.9 \%)$ had rectoceles (Ant 21.4\%; Post 14.2\%; Ant \& Post 7.14\%). Ten patients (50\%) underwent anal manometery, four of them were normal the other four had delayed Squeeze response. Rectal biopsy was ganglionic in all cases. Anal manometery was done to 8 cases (40\%) with half of them showing delayed squeeze. Anal EMG was done to all cases,18 cases (90\%) were normal. MRI was normal in all cases.

Nine cases (45\%) were done by Laparoscopic Assisted Transanal Pull through technique, while 10 cases (50\%) were done by Trans-anal soave Rectosigmoidectomy technique. and only one case (5\%) was done by open technique. Three cases (15\%) had post-operative complications, two of them had leakage (1 case needed temporary colostomy and the other was treated conservatively) and one case had port site infection. The resected segment length ranged from $28.8 \mathrm{~cm}$ to $18.9 \mathrm{~cm}$, the mean length was $22.76 \mathrm{~cm}$, while the diameter ranged from $4 \mathrm{~cm}$ to $7 \mathrm{~cm}$, the mean diameter was $4.93 \mathrm{~cm}$. The more the duration of constipation was the more dilatation and lengthening of the sigmoid in relation to age. All the cases (100\%). had no aganglionic segment. There was high correlation between Rectosigmoidectomy and the improvement of the associated urinary incontinence, all cases suffered from associated urinary incontence were improved postoperatively $(100 \%)(P<0.001)$.

According to the Rome III Criteria results, all 20 patients $(100 \%)$ had two or less bowel movements per week pre-operatively, this percentage has dropped to $10 \% \quad(\mathrm{P}<0.001)$ post-operatively; 15 patients $75 \%$ had fecal incontinence one or more times per week pre-operatively, and 14 patients $70 \%$ had history of stool holding pre-operatively; both dropped to $10 \%$ post-operatively $(\mathrm{P}<0.001)$. While $55 \%$ had history of painful defecations, $30 \%$ had history of large stools that clog of the toilet, and 15\% had large fecal mass retained in the rectum; all these criteria had dropped to $0 \% \quad(\mathrm{P}<0.001)$ postoperatively.

14 cases $(70 \%)$ had history of stool holding preoperatively; both dropped to 2 patients (10\%) postoperatively $(\mathrm{P}<0.001)$. While 11 patients $(55 \%)$ had history of painful defecations, 6 patients (30\%) had history of large stools that clog of the toilet, and 3 patients (15\%) had large fecal mass retained in the rectum; all these criteria has dropped to $(0 \%)$ $(\mathrm{P}<0.001)$ post-operatively(Table-1).

Over all PICS has changed significantly were constipation and incontence score preoperatively was (8.38 \pm 2.99$)$ and $(20.05 \pm 5.36)$ that changed 6 months post operatively to $(23.60 \pm 4.72)$ and $(24.65 \pm 2.64)$ respectively $(\mathrm{P}<0.001$ and $=0.001)$ (Table 2$)$ (Figure 2 $3)$.

\begin{tabular}{|c|c|c|c|c|c|}
\hline \multirow[t]{2}{*}{ ROME III } & \multicolumn{2}{|c|}{ Pre-operative } & \multicolumn{2}{|c|}{$\begin{array}{c}\text { Post-operative } 6 \\
\text { months }\end{array}$} & \multirow[t]{2}{*}{$\mathrm{P}$} \\
\hline & No. & $\%$ & No. & $\%$ & \\
\hline Two or less bowel movements per week & 20 & 100.0 & 2 & 10.0 & $<0.001^{*}$ \\
\hline $\begin{array}{r}\text { Fecal incontinence one or more times per } \\
\text { week }\end{array}$ & 15 & 75.0 & 2 & 10.0 & $<0.001^{*}$ \\
\hline History of stool holding & 14 & 70.0 & 2 & 10.0 & $<0.001^{*}$ \\
\hline History of painful defecations & 11 & 55.0 & 0 & 0.0 & $<0.001^{*}$ \\
\hline History of large stools that clog the toilet & 6 & 30.0 & 0 & 0.0 & $<0.001^{*}$ \\
\hline Large fecal mass retained in the rectum & 3 & 15.0 & 0 & 0.0 & $<0.001^{*}$ \\
\hline
\end{tabular}

Table 1: Comparison between Rome III criteria pre and post operatively 


\begin{tabular}{||c|c|c|c|c||}
\hline & Pre-operative & Post-operative 3 months & Post-operative 6 months & P \\
\hline Incontence Score & & & & \\
Min.- Max. & $6.0-32.0$ & $20.0-32.0$ & $20.0-32.0$ & $0.001^{*}$ \\
Mean \pm SD. & $20.05 \pm 5.36$ & $23.90 \pm 2.57$ & $24.65 \pm 2.64$ & \\
Median (IQR) & $20.0(18.0-22.0)$ & $23.50(22.0-25.50)$ & $24.50(23.0-26.0)$ & \\
\hline Sig.bet.periods & \multicolumn{3}{|c||}{$\mathrm{P}_{1}=0.038^{*}, \mathrm{p}_{2}=0.014^{*}$} & \\
\hline Constipation Score & $0.50-12.0$ & $12.0-28.50$ & $10.0-28.50$ & \\
Min. - Max. & $8.38 \pm 2.99$ & $24.50 \pm 3.61$ & $23.60 \pm 4.72$ & $<0.001^{*}$ \\
Mean \pm SD. & $8.50(6.0-11.0)$ & $25.50(23.25-26.50)$ & $23.75(23.25-26.50)$ & \\
Median (IQR) & \multicolumn{3}{|c|}{$\mathrm{P}_{1}<0.001^{*}, \mathrm{p}_{2}<0.001^{*}$} & \\
\hline Sig.bet.periods & \multicolumn{3}{|c|}{} \\
\hline
\end{tabular}

Table 2: Comparison between the different studied periods according to PICS Pre and Postoperatively 3 and 6 months.

P: p value for comparing between the studied parodies

$\mathrm{P}_{1}$ : $\mathrm{p}$ value for comparing Pre-operative and Postoperative 3 months

$\mathrm{P}_{2}$ : $\mathrm{p}$ value for comparing between Pre-operative and Post-operative 6 months

*: Statistically significant at $\mathrm{p} \leq 0.05$

\section{Constipation Score}

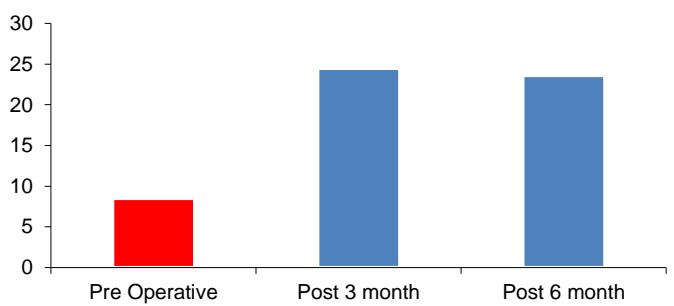

Fig. 2: Constipation Score pre and post-operative

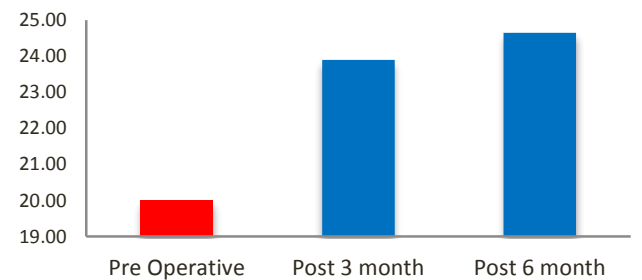

Fig. 3: Incontence score pre -operative and postoperative

\section{DISCUSSION}

According to Levy et al FC was more prominent in females $(2: 1){ }^{8}$ In this study males were prominent $(2: 1)$. Similar result was recorded by Khalil et $\mathrm{al}^{9}$. The mean age of patients in our study was 8 years; which was the same in Luis De la Torre et al. ${ }^{10}$. And, the mean duration of constipation in our study was 4.5 years. We concluded that patient with history of constipation of more than 4 years duration and older than 8 years of age; are most probably in need for surgery. Constipation was evident in all patients in this study, while soiling was evident in $55 \%$ and
$80 \%$ had abdominal distention. this result was close to what was founded by Kuizenga-Wessel et al who recorded results of soiling in $50 \%$ and distention in $66 \%{ }^{11}$. Urinary incontence(nocturnal) was found in $50 \%$ of the cases in this study, Veiga et $\mathrm{al}^{12}$ explained this condition as the effect of the pressure exerted on the urinary bladder by the dilated rectum and colon. Barium Enema was an essential diagnostic tool in this study by which we could exclude all cases of short and ultra-short HD as well as helping the diagnosis of FC by measuring the RPR, Van Der Plas $^{13}$ recommended the same. We strongly recommend rectal biopsy to be an essential procedure for all patients before surgery and this recommendation is in correspondence with Luis De la Torre et $\mathrm{al}^{10}$. We did exclude all cases of aganglionic segment form our study. Although, Defecography is an important investigatory tool that helps determining the anatomical abnormalities (Perineal descent, Rectocele) and physiological abnormalities (Dyssynergia), 70\% of our cases were cooperative to perform this investigation, Suzanne Rose $^{14}$ recommended the same.

Anal EMG was normal in 90\% of the cases. An MRI pelvic Floor muscle was done in cases with abnormal EMG, to exclude cases with anatomical neural deformities (Spina bifida). If Normal MRI was found an initial biofeedback treatment was started as to correct the muscle weakness. We think this is due to long standing constipation causing a chronic strain on the pudendal nerve, which in turn causes muscle weakness that is generally reversible; this also was agreed on by Suzanne Rose ${ }^{14}$. This justifies the need to do Mallon procedure in association with Rectosigmoidectomy, as introduced by Marc levitt et $\mathrm{al}^{3}$ Anal manometery was done in $40 \%$ of the cases in this study, This concept is agreed upon by Meinds, R.J.,Wu, J.F, Frenckner, $\mathrm{B}^{15-17}$ the importance of anal manometery is to be as important as rectal biopsy by many authors.

We used 3 surgical techniques in the Rectosigmoidectomy (Laparoscopic assisted Transanal pull through, open Rectosigmoidectomy, and Transanal soave pull through) after refining our technique from Sigmoidectomy only in only one case to Rectosigmoidectomy in 19 cases. Alberto Pena recorded that insufficient removal of the rectum 
causes significant recurrence. ${ }^{18}$ De la Torre et al $^{10}$ arrived to the same conclusion. Although coloanal anastomosis by Pena has resolved the problem of constipation and the risk of fecal impaction but most of his case series suffered from true fecal incontence that is why we used to remove the upper $1 / 3$ or upper $2 / 3$ of the rectum. The results of improvement of constipation and soiling in our series were 90\% improvement after 6 months. All techniques showed the same results post-operative, with fewer complications in the Transanal soave technique; and one case of post-operative anastomotic stricture with circular stapler. We preferred this technique as we have experience in the usage of Transanal soave technique. Also, the anastomosis in Transanal technique is oblique. The overall success in the patients who had Rectosigmoidectomy was $90 \%$ when measured by Rome III criteria. This agrees with a meta-analysis published by Levitt et $\mathrm{al}^{19}$ with patient satisfaction ranged from $80-100 \%$ after Rectosigmoidectomy. The improvement has always been faster in term of constipation shifting the PICS from an average of 8.36 preoperative to 24.50 in just 3 months postoperative. But with incontence they had a more gradual improvement over the 6 months postoperative. This may be caused by the muscle weakness due to long standing constipation. Or this may be caused by the rectal dilatation which was done intra-operatively. So, we recommend clarifying this matter with the parents so as not encounter any unnecessary conflicts about the effect of surgery in term of incontence. However, several future studies are needed with large number of patients and long period of follow up for determination of the best approach for management of pediatric patients with FC.

\section{CONCLUSION}

Rectosigmoidectomy is the best treatment for children suffering from intractable idiopathic constipation with megarectosigmoid, and is better than Sigmoidectomy alone as the removal of the rectum is essential for better $\mathrm{p}$ toperative results.

Also, We can't recommend a specific technique for Rectosigmoidectomy, however by using stapler the possibility of postoperative complications as leakage and stenosis may occur.

\section{REFERENCES}

1. Wani RA and Thakur N. Physiology of Defecation. In: Chowdri NA, Parray FQ, eds. Benign Anorectal Disorders: A Guide to Diagnosis and Management. Springer India; 2016:7-9.

2. Hakguder G, Ates O, Caglar M, et al. A unique opportunity for the operative treatment of high anorectal malformations: laparoscopy. European journal of pediatric surgery Dec 2006;16(6):449-55.

doi:10.1055/s-2006-924401

3. Gasior A, Brisighelli G, Diefenbach K, et al. Surgical Management of Functional
Constipation: Preliminary Report of a New Approach Using a Laparoscopic Sigmoid Resection Combined with a Malone Appendicostomy. European journal of pediatric surgery: Aug 2017;27(4):336-340. doi:10.1055/s-0036-1593606

4. Preston DM, Lennard-Jones JE and Thomas BM. Towards a radiologic definition of idiopathic megacolon. Gastrointestinal radiology. 1985;10(2):167-9.

5. Fichtner-Feigl S, Sailer $\mathrm{M}$, Höcht $\mathrm{B}$, et al. Development of a New Scoring System for the Evaluation of Incontinence and Constipation in Children. journal article. coloproctology. January 01 2003; 25(1):10-15. doi:10.1007/s00053-003-5084-6

6. Benninga M, Candy DC, Catto-Smith AG, et al. The Paris Consensus on Childhood Constipation Terminology (PACCT) Group. Journal of pediatric gastroenterology and nutrition. Mar 2005;40(3):273-5.

7. Koppen IJ, Lammers LA, Benninga MA, et al. Management of Functional Constipation in Children: Therapy in Practice. Paediatric drugs. $\quad$ Oct 2015;17(5):349-60. doi:10.1007/s40272-015-0142-4

8. Levy EI, Lemmens R, Vandenplas Y, et al. Functional constipation in children: challenges and solutions. Pediatric Health Med Ther. 2017;8:19-27. doi:10.2147/PHMT.S110940

9. Khalil A and Alkot M. Study of functional constipation among children attending the Gastroenterology Clinic at Alexandria University Children\&\#8217;s Hospital. Original Article. Alexandria Journal of Pediatrics. September 1, 2018 2018;31(3):120127.

\section{doi:10.4103/ajop.ajop 2418}

10. De la Torre L, Cogley K, Cabrera-Hernández et al. Transanal proximal rectosigmoidectomy. A new operation for severe chronic idiopathic constipation associated with megarectosigmoid. Journal of pediatric surgery. Nov 2019;54(11):2311-2317. doi:10.1016/j.jpedsurg.2019.04.009

11. Kuizenga-Wessel S, Koppen IJN, Zwager LW, et al. Surgical management of children with intractable functional constipation; experience of a single tertiary children's hospital. Neurogastroenterology and motility: the official journal of the European Gastrointestinal Motility Society. May 2017; 29(5) doi:10.1111/nmo.13005

12. Veiga ML, Lordelo $\mathrm{P}$, Farias $\mathrm{T}$, et al. Constipation in children with isolated overactive bladders. Journal of pediatric urology. Dec 2013; 9 (6 Pt A): 945-9. doi:10.1016/j.jpurol.2013.01.013 
13. van der Plas RN, Benninga MA, Staalman CR, et al. Megarectum in constipation. Archives of disease in childhood. Jul 2000;83(1):52-8. doi:10.1136/adc.83.1.52

14. Rose MDMS. Constipation A Practical Approach to Diagnosis and Treatment. Springer New York: Imprint: Springer. https://link.springer.com/10.1007/978-1-49390332-0

15. Meinds RJ, Trzpis $\mathrm{M}$ and Broens PMA. Anorectal Manometry May Reduce the Number of Rectal Suction Biopsy Procedures Needed to Diagnose Hirschsprung Disease. Journal of pediatric gastroenterology and nutrition. Sep 2018;67(3):322-327. doi:10.1097/mpg.0000000000002000

16. Wu JF, $\mathrm{Lu} \mathrm{CH}$, Yang $\mathrm{CH}$, et al. Diagnostic Role of Anal Sphincter Relaxation Integral in High-Resolution Anorectal Manometry for
Hirschsprung Disease in Infants. The Journal of pediatrics. Mar 2018;194:136-141.e2. doi:10.1016/j.jpeds.2017.10.017

17. Frenckner B. Ano-rectal manometry in the diagnosis of Hirschsprung's disease in infants. Acta paediatrica Scandinavica. Mar 1978;67(2):187-92.

doi:10.1111/j.1651-2227.1978.tb16301.x

18. Levitt MA, Martin CA, Falcone RA, et al. Transanal rectosigmoid resection for severe intractable idiopathic constipation. Journal of pediatric surgery. Jun 2009;44(6):1285-90; discussion 1290-1.

doi:10.1016/j.jpedsurg.2009.02.049

19. Levitt MA, Mathis KL and Pemberton JH. Surgical treatment for constipation in children and adults. Best practice \& research Clinical gastroenterology. Feb 2011;25(1):167-79. doi:10.1016/j.bpg.2010.12.007 